\title{
EDITORIAL
}

\section{DESDE LA CIENCIA AVALADA: UNA POSIBLE SOLUCIÓN A LA SEQUÍA DEL CARIBE COLOMBIANO}

\author{
Alexander Salazar-Ceballos \\ Bacteriólogo. Especialista en Parasitología Humana. Magíster en Biología. Docente programa de Medicina, \\ Universidad del Magdalena. E-mail: alexsal2010@gmail.com
}

La reciente medición de grupos de investigación de Colciencias, dejó sinsabores entre diferentes investigadores, principalmente divididos entre ciencias duras y ciencias blandas, es decir una competencia tácita. Entre algunos datos de estadística descriptiva, cerca de 2.400 grupos reconocidos pertenecen a las áreas de las ciencias exactas y naturales, médicas y de la salud, ingeniería y tecnología y ciencias agrícolas; y cerca de 1.500 grupos reconocidos pertenecen a las ciencias sociales y humanas, y humanidades. Entre las primeras cuatro universidades públicas se encuentran 1.045 grupos avalados, de estos, 502 pertenecen a la Universidad Nacional (con sus 8 sedes) y 247 a la Universidad de Antioquia, y entre las universidades o instituciones públicas del Caribe se encuentran solamente 177 grupos avalados, y se aceptaron cerca de 130.000 artículos científicos con calidad ${ }^{1}$. La medición de los productos se realizó independientemente del tipo de universidad: grande, mediana o pequeña; es de entender que en las universidades líderes en investigación en Colombia tienen más trayectoria (administrativa y más redes de colaboración) en la producción científica en comparación con las universidades medianas o pequeñas, las llamadas "universidades de provincia".

Ahora, si existiera la mencionada segregación, ipor qué no existió un apoyo mutuo entre los investigadores de las distintas universidades? Una de las posibles respuestas sería el ego científico: a través del número de publicaciones se produce un reconocimiento de los grupos de investigación, un nuevo status de "escalafón" entre los investigadores (sénior, asociado, junior) y la acreditación de calidad de los programas y de las universidades. ¿Pero ante todo la ciencia no debería responder a los problemas de la sociedad? ¿O más bien ya sobrepasamos los problemas de la sociedad y el problema de la ciencia es enaltecer el ego? Estas preguntas parecen ser tema de una investigación social, psicológica, psiquiátrica, política y/o económica. Intentaré responder desde problemas que afectan a las diferentes regiones colombianas y a la vez de forma global. Una medición del impacto de la ciencia sobre la sociedad ${ }^{2}$, en el caso de que medir la ciencia fuese ideal, sería medir el impacto de la investigación a un problema derivado del progreso, por ejemplo: el cambio climático, la obesidad, etc.; la medición del impacto es un proceso a largo plazo, la medición a través de artículos científicos es a corto plazo. Otra respuesta sería que estos problemas del progreso solo son de competencia de los políticos. Cabe recordar que en Colombia ya existe la denominada ley contra la obesidad $^{3}$, pero el problema sigue en aumento.

A nivel mundial el sobrepeso y la obesidad son un problema de salud pública, con un $5 \%$ de la mortalidad mundial ${ }^{4,5}$, y el cambio climático es una amenaza de salud pública ${ }^{6}$; la actual sequía en la región Caribe es consecuencia de la alteración del clima por el calentamiento global. Y existen investigaciones, incluso de investigadores colombianos, que promueven el transporte activo, caminar e ir en bicicleta al trabajo o al estudio, con el fin de prevenir la obesidad y disminuir el uso de vehículos disminuyendo así el aporte de $\mathrm{CO}_{2}$ al medio ambiente $e^{7-13}$. Imagino que esta interrelación es difícil de comprender, dado que el carro en nuestra sociedad se ha convertido en un ícono de desarrollo y progreso, pero también es uno de los principales causantes del actual cambio climático. 
Entonces, si investigo acerca de "X" proteína o gen de algún microorganismo "Y", ime debería preocupar por el cambio climático?; más bien, desde la evidencia científica, la Pseudomonas syringae sintetiza unas proteínas de membrana que le permiten catalizar la congelación del agua a una temperatura entre $-2^{\circ} \mathrm{C}$ y $-4{ }^{\circ} \mathrm{C}$, el agua pura congela a $-40^{\circ} \mathrm{C}^{14}$, actuando como un núcleo integrador de hielo, y así a partir de la congelación la bacteria infecta el maíz, generando pérdidas agrícolas. También se ha observado que esta bacteria se encuentra en todas las formas de precipitación, ahí es donde viene la pregunta de investigación: ise podría producir lluvia a partir de la generación de determinadas cantidades de P. syringae, es decir: bioprecipitación? La respuesta parece ser muy probable, teniendo en cuenta que se han encontrado cantidades considerables en forma natural de $P$. syringae en las diferentes formas de precipitación ${ }^{15}$. Finalmente es posible que los laboratorios de ciencias básicas de las universidades élite de investigación generen $P$. syringae, liberarla al medio ambiente en el Caribe colombiano y así contribuir a la producción de lluvias, (aliviando la actual sequía, la cual es producto del Fenómeno de El Niño pronosticado desde el 2014), y la medición de estos resultados estarían de la mano de las universidades del Caribe y las universidades de élite; también se deben analizar los posibles efectos adversos. Esperando que la anterior propuesta en un futuro sea viable, se tendría un problema "real" de ciencia para solucionar.

Pero, ipor qué mirar al Caribe colombiano? En el Caribe colombiano se encuentran Cartagena y Santa Marta, dos de los principales destinos turísticos del país y sedes de grandes eventos científicos, tanto nacionales como internacionales $i \mathrm{O}$ algún investigador colombiano no ha presentado sus ponencias en el Caribe? iO desea planear sus vacaciones en el Caribe, o ya disfrutó del paraíso del Caribe? Sin olvidar que una de la zonas más afectadas por la actual sequía es la Guajira, inolvidable por sus inhóspitos paisajes y sus etnias de gran fortaleza ante la adversidad de la naturaleza.

Los investigadores y los administradores de la ciencia no pueden seguir en sus torres de marfil, esta es una invitación a solucionar problemas "reales" de nuestra sociedad, solución que beneficiará tanto al sector económico como a los ciudadanos del común. El Caribe también es un paraíso ¡si llueve!

\section{REFERENCIAS BIBLIOGRÁFICAS}

1. Colciencias. Convocatoria Nacional para el Reconocimiento y Medición de Grupos de Investigación, Desarrollo Tecnológico o de Innovación y para el Reconocimiento de Investigadores del Sistema Nacional de Ciencia, Tecnología e Innovación, 2014. Convocatoria 693 de 2014-Colciencias. Informe de publicación de la publicación de los resultados finales. Abril 20 de 2015, Bogotá.

2. Godin B, Doré C. Measuring the impacts of science: beyond the economic dimensión. [Internet] [citado el 27 de abril de 2015]. Disponible en: http://www.csiic. ca/PDF/Godin_Dore_Impacts.pdf

3. Ley $\mathrm{N}^{\circ} 1355$ del 14 de Octubre de 2009, Congreso de Colombia. Artículo 5 y 6 . "Por medio de la cual se define la obesidad y las enfermedades crónicas no transmisibles asociadas a ésta como una prioridad de salud pública y se adoptan medidas para su control, atención y prevención” [Internet] [citado el 4 de diciembre de 2014]. Disponible en: http://www.coldeportes.gov.co/coldeportes/index. php?idcategoria $=53626$

4. Organización Mundial de la Salud, Ginebra, Suiza. [Internet] 2010. Recomendaciones mundiales sobre actividad física para la salud [citado el 27 de abril de 2015]. Disponible en: http://whqlibdoc.who.int/ publications/2010/9789243599977_spa.pdf

5. Maibach E, Steg L, Anable J. Promoting physical activity and reducing climate change: Opportunities to replace short car trips with active transportation. Preventive Medicine. 2009; 49:326-327.

6. World Health Organization. Protecting health from climate change: connecting science, policy and people. [Internet] 2009. Denmark. [citado el 27 de abril de 2014]. Disponible en: http://www.who.int/ globalchange/publications/reports/9789241598880/ en/.

7. Nazelle A, Morton BJ, Jerrett M, Crawford-Brown D. Short trips: An opportunity for reducing mobile-source emissions? Transportation Research Part D. 2010; 15: 451-457.

8. Varela M., Duarte C., Salazar I., Lema L., Tamayo J. Actividad física y sedentarismo en jóvenes universitarios de Colombia: prácticas, motivos y recursos para realizarlas. Colomb Med. 2011; 42: 269-77 
9. González S, Sarmiento O, Lozano O, Ramírez A, Grijalba C. Niveles de actividad física de la población colombiana: desigualdades por sexo y condición socioeconómica. Rev Biomédica. 2014; 34:447-59.

10. Mendoza D, García D, Jaimes C. Actividad física en el tiempo libre y auto percepción del estado de salud en la población colombiana. Trabajo para optar el título de especialista en epidemiología.[Tesis]. Bogotá (Colombia): Universidad CES, Colegio Mayor de Nuestra Señora del Rosario, Facultad de Medicina, Especialización en Epidemiología, julio 2010.

11. Torres A, Sarmiento OL, Stauber C, Zarama R. The Ciclovia and Cicloruta Programs: Promising Interventions to Promote Physical Activity and Social Capital in Bogotá, Colombia. Am J Public Health. 2013;103:e23-e30. doi:10. 2105/AJPH.2012.301142.
12. Sarmiento OL, Torres A, Jacoby E, Pratt M, Schmid TL, Stierling G. La Ciclovía-Recreativa: Un Programa Masivo de Recreación con Potencial en Salud Pública. Journal of Physical Activity and Health, 2010, 7(Suppl 2), S163-S180.

13. Mosquera J, Reis R, Frank L, Ramírez-Marrero, Arriaga E, Méndez F, et al. Transport and health: a look at three Latin American cities. Cad. Saúde Pública. 2013;29(4):654-666. http://dx.doi.org/10.1590/S0102311X2013000800004.

14. Cochet N, Widehem P. Ice crystallization by Pseudomonas syringae. Appl Microbiol Biotechnol. 2000;54:153-161.

15. Prasant M, Ramesh N, Gothandam KM, Sivamangala K, Shantini T. Pseudomonas syringae: an overview and its future as a "rain making bacteria". Int Res J Bio Sci. 2015;4(2):70-77. 